\title{
Angiopoietin-2 as a predictor of fibrosis regression in chronic hepatitis $C$ virus patients after direct-acting antiviral drugs
}

\author{
Amira Isaac ${ }^{*}$, Tarek Maged El Sakaty, Sarah Hamdan Hussein and Hany Samir Rasmy
}

\begin{abstract}
Background: HCV infection is a major health concern. Disease progression to fibrosis, cirrhosis, and HCC is aided by the persistence of inflammatory reactions and cellular damage. Moreover, angiogenesis was found to have a substantial pathogenic role in disease progression. Serum Angiopoietin-2 appears to be correlated with liver stiffness in chronic HCV and its elevation is linked to disease progression from chronic hepatitis to cirrhosis. The aim of this study was to evaluate the role of serum Angiopoietin-2 in the prediction of regression of fibrosis in chronic HCV patients receiving direct-acting antiviral agents. Forty Egyptian chronic HCV patients for whom direct-acting antiviral agent (DAA) therapy was planned were included. All patients underwent assessment twice, at baseline and at SVR12, for standard laboratory tests, measurement of fibrosis using FibroScan, FIB-4 and APRI scores, and Angiopoietin-2 level.

Results: Statistically significantly higher levels of baseline Ang-2 were detected with the progression of fibrosis stages with a $p$-value of $<0.001$. The best cutoff value of baseline Ang- 2 in discrimination of liver cirrhosis (F4) from F0-F3 was $>630 \mathrm{pg} / \mathrm{ml}$ with $85.71 \%$ sensitivity and $84.85 \%$ specificity. A statistically significant decline of Ang-2 (from $464.3 \pm 237.2 \mathrm{pg} / \mathrm{ml}$ to $401.3 \pm 277.1 \mathrm{pg} / \mathrm{ml}$ ) was noted after the achievement of SVR12 with a $p$-value $<0.001$. Regression of liver fibrosis in this study is defined as a decrease of more than or equal to one stage in liver fibrosis. Lower baseline fibrosis stages and other non-invasive scoring systems (FIB-4 and APRI scores) were associated with regression of fibrosis following successful DAAs treatment. However, higher baseline Ang-2 levels were significantly associated with non-regression of fibrosis, and at a cutoff of $>680 \mathrm{pg} / \mathrm{ml}$, it might predict non-regression of fibrosis after successful eradication of HCV with DAAs with $93.33 \%$ sensitivity and $70 \%$ specificity.
\end{abstract}

Conclusions: Angiopoietin-2 can be a useful predictor of fibrosis regression in chronic HCV patients receiving directacting antiviral agents. Elevated baseline Angiopoietin-2 and advanced fibrosis stages may predict non-regression of liver fibrosis.

Keywords: Hepatitis C virus, Angiopoietin-2, Direct-acting antivirals

\section{Background}

Hepatitis C virus (HCV) is a global health concern. It is thought to infect 130-170 million people worldwide [1], and about 70 million have chronic hepatitis $\mathrm{C}(\mathrm{CHC})[2]$.

The main triggering factor of $\mathrm{CHC}$ advancement is $\mathrm{HCV}$ persistence within the liver tissue, which maintains

\footnotetext{
*Correspondence: dr.amira@med.asu.edu.eg

Internal Medicine Department, Gastroenterology \& Hepatology unit

Faculty of Medicine Ain Shams University, Cairo, Egypt
}

the inflammatory reactions and disrupts healing mechanisms, leading to angiogenesis, fibrosis, cirrhosis, and hepatocellular carcinoma (HCC) [3].

Direct-acting antiviral agents (DAAs) have revolutionized HCV treatment with a sustained virological response (SVR) exceeding 95\% [4]. Most patients achieving SVR experience a reduction in liver fibrosis and have a lower risk of developing HCC [5].

However, some patients may develop liver fibrosis deterioration and/or HCC following successful $\mathrm{HCV}$ 
eradication with IFN or DAAs. Thus, predicting changes in liver fibrosis following HCV treatment is a crucial clinical concern [6].

Angiogenesis has been linked to $\mathrm{CHC}$ liver injury, with elevated levels of angiogenetic markers such as vascular endothelial growth factor (VEGF) and Angiopoietins in CHC patients [7].

Angiopoietins are a group of vascular growth factors, with Angiopoietin-1 (Ang-1) and Angiopoietin-2 (Ang2) being the most well-studied. These are tyrosine kinase receptor Tie-2 legends [8]. Ang-1 helps to sustain vascular networks by acting as a preservation factor for the endothelium and boosting pericytes and smooth muscle cell recruitment, thereby stabilizing vascular networks. Ang-2 is a biological Ang-1 antagonist that is highly expressed at vascular remodeling sites. It lowers vascular stability and makes VEGF more accessible to endothelial cells [9].

The aim of this study is to evaluate the role of serum Angiopoietin-2 in the prediction of fibrosis regression in chronic hepatitis $\mathrm{C}$ virus patients receiving direct-acting antiviral agents.

\section{Methods}

This prospective study was carried out on 40 Egyptian chronic HCV patients for whom DAA therapy was planned by the National Committee for Control of Viral Hepatitis (NCCVH) conforming to the ethical guidelines of the Declaration of Helsinki, during the period from April 2019 to December 2019.

Chronic $\mathrm{HCV}$ patients had positive $\mathrm{HCV}$ Ab for at least 6 months, and detectable quantitative HCV RNA. During the study, they were offered an individually customized DAA regimen of sofosbuvir $400 \mathrm{mg}+$ daclatasvir $60 \mathrm{mg} \pm$ ribavirin $1000-1200 \mathrm{mg}$ for 3 months according to the Egyptian NCCVH protocol [10].

Co-infection with HBV or HIV, HCC, or extra-hepatic malignancies (except after 2 years of disease-free interval); pregnancy; severe renal impairment; previous or current heavy alcohol consumption; failure to achieve SVR; Child C cirrhosis; or previous DAAs treatment experience were all considered exclusion criteria.

I- Before enrollment in the study, all patients underwent the following:

- Full history taking

- Thorough clinical examination for stigmata of chronic liver disease.

- Laboratory assessment including:

O Full hepatic profile O Alpha-fetoprotein
O Complete blood count

O HCV quantitative RNA via polymerase chain reaction (PCR)

O HBsAg, HCVAb, and HIVAb

O Serum creatinine level

O Angiopoietin-2 (Ang-2) measured by ELISA, Cat. No:E1221Hu, Human Angiopoietin-2 Quantikine Kit according to manufacturer instructions.

- Abdominal ultrasound: with an emphasis on liver size and echogenicity, splenic bi-polar diameter, ascites, focal lesions, and portal vein diameter. - Calculating APRI score: The AST to Platelet Ratio Index (AST (IU/L)/AST upper normal level $(\mathrm{IU} / \mathrm{L}))$ /platelet count $\left(10^{9} / \mathrm{L}\right) \times 100$ [11].

- Calculating FIB-4 index: The Fibrosis-4 index is calculated as: [Age (years) $\times$ AST(IU/L)]/ [platelet count $\left.\left(10^{9} / \mathrm{L}\right) \times \mathrm{ALT} 1 / 2(\mathrm{IU} / \mathrm{L})\right][12]$.

- Transient elastography: FibroScan ${ }^{\circledR}$ (Echosens, Paris, France). Liver stiffness measurement (LSM) was expressed in kilopascal $(\mathrm{kPa})$ as $\mathrm{F} 0-\mathrm{F} 1,2.5-$ $6.9 \mathrm{kPa}$; F2, 7.0-9.4 kPa; F3, 9.5-12.4 kPa; and F4, greater than or equal to $12.5 \mathrm{kPa}$ [13].

II- All participants were followed up and evaluated by HCV RNA quantitation, Angiopoietin-2, FIB-4 index, APRI score, and LSM by FibroScan before and 12 weeks after end of treatment (EOT).

Data were analyzed using the IBM SPSS V20. Descriptive statistics were computed for quantitative data as mean and standard deviation. For qualitative data, chisquare and marginal homogeneity tests were used. The paired $t$-test, Mann-Whitney $U$, Wilcoxon rank, and Kruskal-Wallis tests were used for quantitative data. Significance level was as follows: $p$-value $<0.05$ is significant and $<0.01$ is highly significant, otherwise is insignificant.

\section{Results}

This study included forty chronic $\mathrm{HCV}$ patients, comprising 26 (65\%) males and 14 (35\%) females. Their mean age was $52.35 \pm 6.08$. The median of their HCV-RNA was $6.20(5.30-6.65) \log 10 \mathrm{IU} / \mathrm{ml}$.

All patients experienced treatment with a personally tailored DAA regimen, with successful HCV eradication 12 weeks after DAA termination, There had been a significant improvement in most laboratory tests except for the hemoglobin and platelet count (Table 1).

On evaluation of LSM by FibroScan and calculating FIB-4 and APRI scores, there were statistically significant improvement of their values 12 weeks after EOT indicating regression of hepatic fibrosis (Tables 2 and 3 ). 
Table 1 Comparison between different laboratory parameters before and 12 weeks after EOT

\begin{tabular}{|c|c|c|c|c|c|}
\hline Variables & & Before treatment & $\begin{array}{l}12 \text { weeks after } \\
\text { treatment }\end{array}$ & Test of significance & $P$-value \\
\hline \multirow[t]{2}{*}{ Hemoglobin (g/dL) } & Mean \pm SD & $13.39 \pm 1.49$ & $13.28 \pm 1.50$ & $t=1.713$ & 0.095 \\
\hline & Range & $10.80-16.40$ & $10.70-16.40$ & & \\
\hline \multirow[t]{2}{*}{$\operatorname{TLC}\left(\times 10^{3} / \mathrm{mL}\right)$} & Mean \pm SD & $5.46 \pm 1.46$ & $5.52 \pm 1.51$ & $t=3.028^{*}$ & $0.004^{*}$ \\
\hline & Range & $2.50-8.80$ & $2.50-9.0$ & & \\
\hline \multirow{2}{*}{$\begin{array}{l}\text { Platelets } \\
\left(\times 10^{3} / \mathrm{mL}\right)\end{array}$} & Mean \pm SD & $254.9 \pm 91.45$ & $252.1 \pm 87.51$ & $t=1.657$ & 0.106 \\
\hline & Range & $84.0-426.0$ & $103.0-420.0$ & & \\
\hline \multirow{2}{*}{$\begin{array}{l}\text { AST } \\
\text { (IU/L) }\end{array}$} & Mean \pm SD & $37.25 \pm 13.95$ & $33.10 \pm 13.74$ & $Z=5.102^{*}$ & $<0.001^{*}$ \\
\hline & Range & $22.0-70.0$ & $20.0-65.0$ & & \\
\hline \multirow{2}{*}{$\begin{array}{l}\text { ALT } \\
\text { (IU/L) }\end{array}$} & Mean \pm SD & $38.33 \pm 10.52$ & $34.30 \pm 9.99$ & $t=5.801^{*}$ & $<0.001 *$ \\
\hline & Range & $25.0-65.0$ & $20.0-58.0$ & & \\
\hline \multirow[t]{2}{*}{ Albumin (g/dL) } & Mean \pm SD & $3.88 \pm 0.35$ & $4.05 \pm 0.33$ & $t=9.837^{*}$ & $<0.001^{*}$ \\
\hline & Range & $3.0-4.60$ & $3.30-4.70$ & & \\
\hline \multirow[t]{2}{*}{ Total bilirubin (mg/dL) } & Mean \pm SD & $0.85 \pm 0.44$ & $0.73 \pm 0.32$ & $Z=5.520^{*}$ & $<0.001^{*}$ \\
\hline & Range & $0.30-2.0$ & $0.28-1.80$ & & \\
\hline \multirow[t]{2}{*}{ INR } & Mean \pm SD & $1.12 \pm 0.18$ & $0.97 \pm 0.15$ & $t=6.376^{*}$ & $<0.001^{*}$ \\
\hline & Range & $0.89-1.60$ & $0.79-1.50$ & & \\
\hline
\end{tabular}

t paired t-test, Z Wilcoxon signed-ranks test, * significant

Table 2 Comparison between patients before and 12 weeks after EOT regarding APRI score, FIB-4 index, and FibroScan

\begin{tabular}{lllll}
\hline Variables & & Before treatment & $\mathbf{1 2} \mathbf{w}$ after treatment & Test of significance \\
\hline FibroScan $(\mathbf{k P a})$ & Mean \pm SD. & $8.96 \pm 3.38$ & $7.21 \pm 3.57$ & $t=9.937^{*}$ \\
& Range & $2.50-16.30$ & $1.0-15.40$ & $Z=4.995^{*}$ \\
FIB-4 & Mean \pm SD. & $1.51 \pm 1.11$ & $1.31 \pm 0.90$ & $<0.001^{*}$ \\
& Range & $0.47-5.16$ & $0.44-4.14$ & $Z=4.445^{*}$ \\
APRI Score & Mean \pm SD. & $0.47 \pm 0.40$ & $0.38 \pm 0.32$ & $<0.001^{*}$ \\
& Range & $0.20-1.90$ & $0.10-1.50$ & $<0.001^{*}$ \\
\hline
\end{tabular}

$t$ paired $t$-test, $Z$ Wilcoxon signed-ranks test, * significant

Table 3 Comparison between patients before and 12 weeks after EOT regarding FibroScan stages

\begin{tabular}{|c|c|c|c|c|c|c|}
\hline \multirow[t]{2}{*}{ Fibrosis staging } & \multicolumn{2}{|c|}{ Before treatment } & \multicolumn{2}{|c|}{12 weeks after treatment } & \multirow[t]{2}{*}{ MH } & \multirow[t]{2}{*}{$p$} \\
\hline & No. & $\%$ & No. & $\%$ & & \\
\hline Fo/1 & 14 & 35.0 & 23 & 57.5 & $32.0^{*}$ & $<0.001^{*}$ \\
\hline F2 & 11 & 27.5 & 8 & 20.0 & & \\
\hline F3 & 8 & 20.0 & 3 & 7.5 & & \\
\hline F4 & 7 & 17.5 & 6 & 15.0 & & \\
\hline
\end{tabular}

$\mathrm{MH}$ marginal homogeneity test, * significant

Statistically significantly higher levels of baseline Ang-2 were noted with progression of fibrosis stages by FibroScan with $p$ value $<0.001$ (Table 4 ).

A statistically significant decline of Ang-2 (from $464.3 \pm 237.2$ to $401.3 \pm 277.1 \mathrm{pg} / \mathrm{ml}$ ) was noted after achievement of SVR12 with $p$ value $<0.001$ (Table 5), with significant reduction in its levels among
F0-F3 patients, while F4 patients experienced insignificant reduction (Table 6).

Different correlations between Ang-2 levels before and 12 weeks after treatment termination are shown in Table 7.

The best cutoff value of baseline Ang-2 in discrimination of liver cirrhosis (F4) from F0-F3 was $>630 \mathrm{pg} / \mathrm{ml}$ 
Table 4 Relation between Angiopoietin-2 and fibrosis staging before treatment

\begin{tabular}{lllll}
\hline $\begin{array}{l}\text { Fibrosis staging } \\
\text { before treatment }\end{array}$ & $\mathbf{N}$ & $\begin{array}{l}\text { Angiopoietin-2 } \\
\text { before treatment } \\
\text { Mean } \pm \text { SD. }\end{array}$ & Hor $\boldsymbol{~}$ & $\boldsymbol{p}$ \\
\hline F0/1 & $\mathbf{1 4}$ & $300.7 \pm 45.31$ & $29.006^{*}$ & $0.001^{*}$ \\
F2 & $\mathbf{1 1}$ & $314.6 \pm 41.08$ & & \\
F3 & $\mathbf{8}$ & $605.0 \pm 125.9$ & & \\
F4 & $\mathbf{7}$ & $908.571 \pm 91.365$ & \\
\hline
\end{tabular}

H Kruskal-Wallis test, U Mann-Whitney test, ${ }^{*}$ significant

with $85.71 \%$ sensitivity and $84.85 \%$ specificity (Table 8 , Fig. 1).

Regression of liver fibrosis stage in this study is defined as a decrease of more than or equal one stage in liver fibrosis for patients with stages from F2 to F4 data, and in patients with liver fibrosis F0/1, liver fibrosis stage did not worsen.

Subsequently, we analyzed different laboratory parameters associated with non-regression of LSM after successful HCV eradication by DAAs as lower baseline platelets and albumin and higher baseline AST, ALT, bilirubin, and INR (Table 9).

Lower baseline fibrosis stages and other non-invasive scoring system parameters (FIB-4 and APRI scores) were associated with regression of fibrosis following successful DAAs treatment (Table 9).

In evaluating Ang-2 as a possible predictor for regression of fibrosis after successful DAAs treatment, baseline higher levels were significantly associated with nonregression of fibrosis (Table 10).
Table 7 Correlation between Angiopoietin-2 and different parameters

\begin{tabular}{llllll}
\hline & \multicolumn{2}{l}{ Angiopoietin-2 } \\
\cline { 2 - 3 } & \multicolumn{2}{l}{ Before treatment } & & \multicolumn{2}{l}{ After treatment } \\
\cline { 2 - 2 } \cline { 5 - 6 } & $\mathbf{r}_{\mathbf{s}}$ & & & $\mathbf{r}_{\mathrm{s}}$ & $\boldsymbol{p}$ \\
\hline WBC & -0.402 & $0.010^{*}$ & & -0.260 & 0.105 \\
Hb & -0.262 & 0.103 & & -0.259 & 0.106 \\
PLT & -0.245 & 0.128 & & -0.256 & 0.110 \\
AST & 0.541 & $<0.001^{*}$ & & 0.562 & $<0.001^{*}$ \\
ALT & 0.600 & $<0.001^{*}$ & & 0.502 & $0.001^{*}$ \\
Bilirubin & 0.624 & $<0.001^{*}$ & & 0.666 & $<0.001^{*}$ \\
INR & 0.557 & $<0.001^{*}$ & & 0.039 & 0.812 \\
Albumin & -0.429 & $0.006^{*}$ & & -0.361 & $0.022^{*}$ \\
LSM & 0.825 & $<0.001^{*}$ & & 0.614 & $<0.001^{*}$ \\
FIB-4 & 0.620 & $<0.001^{*}$ & & 0.689 & $<0.001^{*}$ \\
APRI & 0.635 & $<0.001^{*}$ & & 0.704 & $<0.001^{*}$ \\
PV & 0.379 & $0.016^{*}$ & & 0.254 & 0.114 \\
\hline
\end{tabular}

$r_{\mathrm{s}}$ Spearman coefficient, ${ }^{*}$ significant

Ultimately, baseline Ang-2 at a cutoff of $>680 \mathrm{pg} / \mathrm{ml}$ might predict non-regression of fibrosis after successful eradication of $\mathrm{HCV}$ with DAAs with $93.33 \%$ sensitivity and $70 \%$ specificity (Table 11, Fig. 2).

\section{Discussion}

$\mathrm{HCV}$ infection is a major health concern because it causes persistent liver damage. Disease progression to fibrosis, cirrhosis, and HCC is aided by the persistence of inflammatory reactions and cellular damage [14].

Table 5 Comparison between levels of Angiopoietin-2 before and 12 weeks after EOT

\begin{tabular}{|c|c|c|c|c|c|}
\hline Variable & & Before treatment & $\begin{array}{l}12 \text { weeks after } \\
\text { treatment }\end{array}$ & $z$ & $P$ \\
\hline \multirow[t]{2}{*}{ Angiopoietin-2 pg/ml } & Mean \pm SD. & $464.3 \pm 237.2$ & $401.3 \pm 277.1$ & $5.157^{*}$ & $<0.001^{*}$ \\
\hline & Range & $240.0-1080.0$ & $110.0-1000.0$ & & \\
\hline
\end{tabular}

Z Wilcoxon signed-ranks test, ${ }^{*}$ significant

Table 6 Comparison between levels of Angiopoietin-2 before and 12 weeks after EOT according to fibrosis stages

\begin{tabular}{|c|c|c|c|c|c|c|c|}
\hline & & \multicolumn{2}{|l|}{ Angiopoietin-2 } & \multicolumn{2}{|c|}{ Differences } & \multicolumn{2}{|c|}{ Paired Test } \\
\hline & & Before treatment & 12 weeks after treatment & Mean & SD & $\mathrm{t}$ & $P$-value \\
\hline \multirow[t]{2}{*}{ F0-F3 } & Range & $240-720$ & $110-700$ & 77.879 & 76.598 & 5.841 & $<0.001^{*}$ \\
\hline & Mean \pm SD & $375.455 \pm 140.492$ & $297.576 \pm 171.647$ & & & & \\
\hline \multirow[t]{2}{*}{ F4 } & Range & 830-1080 & $820-1000$ & 18.571 & 28.536 & 1.722 & 0.136 \\
\hline & Mean \pm SD & $908.571 \pm 91.365$ & $890.000 \pm 65.574$ & & & & \\
\hline \multirow[t]{2}{*}{ T-Test } & $t$ & -9.565 & -8.917 & & & & \\
\hline & $P$-value & $<0.001^{*}$ & $<0.001^{*}$ & & & & \\
\hline
\end{tabular}


Table 8 Agreement for pretreatment Angiopoietin-2 (pg/ml) in discrimination of F4 cirrhosis $(n=7)$ from F0-F3 ( $n=33)$

\begin{tabular}{lllllllll}
\hline & AUC & $\boldsymbol{p}$ & $\mathbf{9 5 \%} \mathrm{Cl}$ & Cut off & Sensitivity & Specificity & PPV & NPV \\
\hline Angiopoietin-2 & 0.978 & $<0.001^{*}$ & $0.932-1.024$ & $>630$ & 85.71 & 84.85 & 54.5 & 96.6 \\
\hline
\end{tabular}

*significant

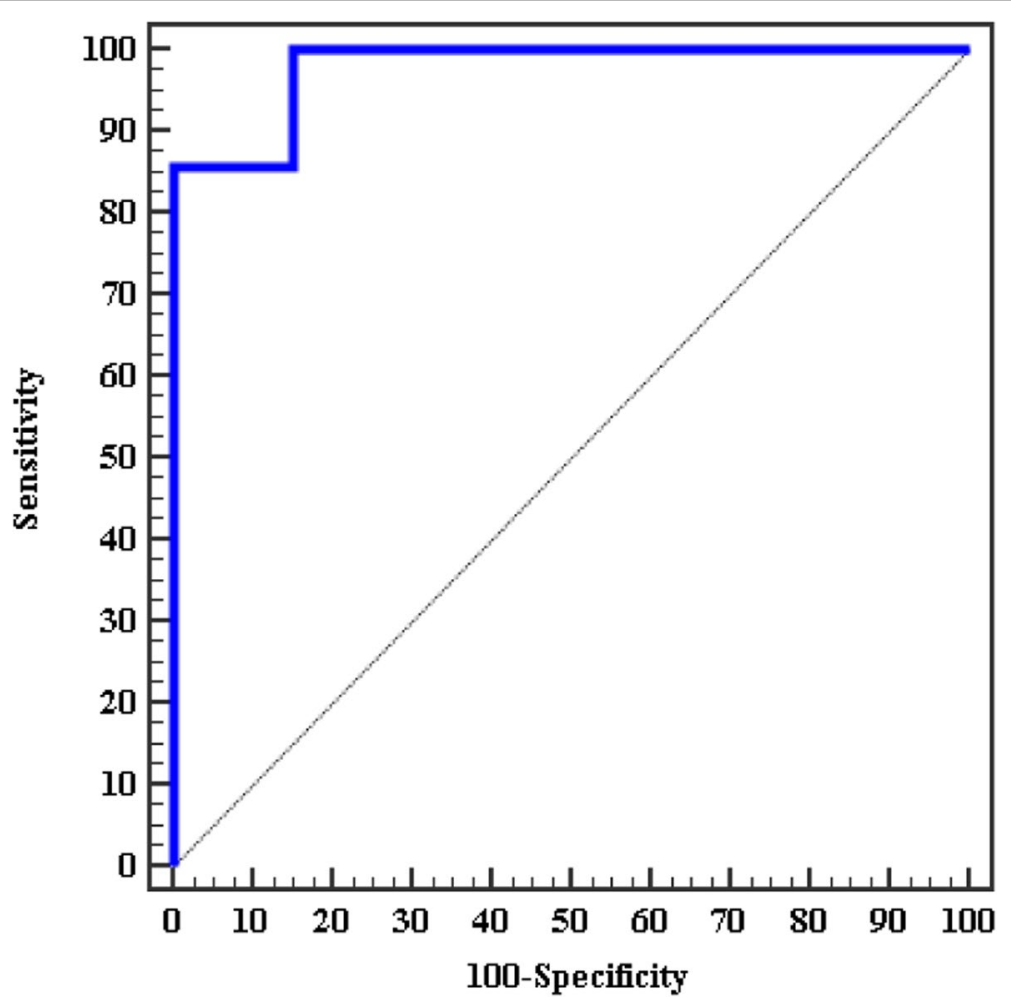

Fig. 1 ROC curve for pretreatment Angiopoietin-2 in discrimination of F4 cirrhosis from F0-F3

As a result, accurate assessment of hepatic fibrosis has emerged as a fundamental priority during management of CHC progression [15].

Liver fibrosis is caused by an inappropriate woundhealing response to persistent injury, which results in excessive matrix deposition and scarring, altering the structure and function of the liver [16]. Angiogenesis is encouraged at the same time to provide oxygen and nutrients to the injured tissues. However, chronic damage disrupts the repairing processes, resulting in restricting blood supply, exacerbating tissue injury, fibrogenesis, and angiogenesis [17].

Through antagonistic autophosphorylation of the tyrosine kinase receptor, Tie2, Ang-2 is a potent regulator of neovascularization, vascular remodeling, and maturation; it is also one of the most important signaling pathways in $\mathrm{HCC}$ [18].

DAAs are ground-breaking anti-HCV medications, with effective elimination of $\mathrm{HCV}$ in most patients. Yet, sometimes even after successful HCV eradication, liver function deterioration and development of HCC are observed, which may be linked to the progression of fibrosis. Thus, evaluating liver fibrosis regression following successful HCV eradication is an important issue [19].

The aim of our study is to evaluate the role of Angiopoietin-2 in the prediction of regression of fibrosis following successful HCV eradication with DAAs.

Our study showed significant improvement in ALT, AST, and hepatic synthetic functions (albumin, bilirubin, and INR) at SVR12 with a $P$ value of $<0.001$. This agreed with van der Meer et al. [20], who found that ALT, AST, and alkaline phosphatase significantly declined 12 weeks after successful DAA treatment.

On assessment of hepatic fibrosis with transient elastography (FibroScan ${ }^{\circledR}$ ), the current study revealed a significant downstaging of fibrosis and LSM degree (from $8.96 \pm 3.38$ to $7.21 \pm 3.57) \mathrm{kPa}$ after successful HCV eradication with a $p$ value $<0.001$. These results agreed with Bachofner et al. [21] who detected a significant decline in 
Table 9 Comparison between patients with and without fibrosis regression regarding different laboratory parameters, liver stiffness, and other fibrosis scoring systems

\begin{tabular}{|c|c|c|c|c|c|c|c|}
\hline & & \multicolumn{4}{|l|}{ Group } & \multicolumn{2}{|l|}{$T$-Test } \\
\hline & & \multicolumn{2}{|l|}{ Regression } & \multicolumn{2}{|l|}{ Non-regression } & $t$ & $P$-value \\
\hline$T$-test & & & & & & $t$ & $P$-value \\
\hline \multirow[t]{2}{*}{ PLT } & Range & $84-426$ & & $92-325$ & & 2.789 & $0.008^{*}$ \\
\hline & Mean \pm SD & $276.367 \pm 86.146$ & & $190.400 \pm 78.543$ & & & \\
\hline \multirow[t]{2}{*}{ AST } & Range & $22-64$ & & $25-70$ & & -3.648 & $0.001^{*}$ \\
\hline & Mean \pm SD & $33.200 \pm 10.350$ & & $49.400 \pm 16.715$ & & & \\
\hline \multirow[t]{2}{*}{ ALT } & Range & $25-65$ & & $28-63$ & & -2.771 & $0.009^{*}$ \\
\hline & Mean \pm SD & $35.867 \pm 8.908$ & & $45.700 \pm 11.963$ & & & \\
\hline \multirow[t]{2}{*}{ Bilirubin } & Range & $0.3-1.4$ & & $0.53-2$ & & -5.588 & $<0.001^{*}$ \\
\hline & Mean \pm SD & $0.676 \pm 0.243$ & & $1.356 \pm 0.528$ & & & \\
\hline \multirow[t]{2}{*}{ INR } & Range & $0.89-1.4$ & & $1.05-1.6$ & & -5.303 & $<0.001^{*}$ \\
\hline & Mean \pm SD & $1.059 \pm 0.087$ & & $1.320 \pm 0.228$ & & & \\
\hline \multirow[t]{2}{*}{ Albumin } & Range & $3.4-4.6$ & & $3-4.1$ & & 3.148 & $0.003^{*}$ \\
\hline & Mean \pm SD & $3.967 \pm 0.315$ & & $3.600 \pm 0.330$ & & & \\
\hline Chi-square & & $N$ & $\%$ & $N$ & $\%$ & $x^{2}$ & $P$-value \\
\hline \multirow[t]{2}{*}{ Fibrosis staging } & F0-F3 & 29 & 96.67 & 4 & 40.00 & 16.681 & $<0.001^{*}$ \\
\hline & F4 & 1 & 3.33 & 6 & 60.00 & & \\
\hline$T$-test & & & & & & $t$ & $P$-value \\
\hline \multirow[t]{2}{*}{ LSM } & Range & $2.5-14.7$ & & $7.9-16.3$ & & -4.255 & $<0.001^{*}$ \\
\hline & Mean \pm SD & $7.863 \pm 2.829$ & & $12.240 \pm 2.776$ & & & \\
\hline \multirow[t]{2}{*}{ FIB-4 } & Range & $0.47-4.72$ & & $0.8-5.16$ & & -3.958 & $<0.001^{*}$ \\
\hline & Mean \pm SD & $1.172 \pm 0.751$ & & $2.541 \pm 1.404$ & & & \\
\hline \multirow[t]{2}{*}{ APRI } & Range & $0.2-1.9$ & & $0.2-1.6$ & & -3.460 & $0.001^{*}$ \\
\hline & Mean \pm SD & $0.360 \pm 0.311$ & & $0.810 \pm 0.472$ & & & \\
\hline
\end{tabular}

*significant

Table 10 Comparison between pretreatment and 12 weeks after EOT Angiopoietin-2 levels in patients with and without fibrosis regression

\begin{tabular}{|c|c|c|c|c|c|}
\hline & & \multicolumn{2}{|l|}{ Group } & \multicolumn{2}{|l|}{$T$-test } \\
\hline & & Regression & Non-regression & $t$ & $P$-value \\
\hline \multirow[t]{2}{*}{ Ang-2 before treatment } & Range & $240-1080$ & $260-960$ & -4.102 & $<0.001^{*}$ \\
\hline & Mean \pm SD & $391.667 \pm 184.112$ & $700.000 \pm 263.944$ & & \\
\hline \multirow[t]{2}{*}{ Ang-2 12 weeks after treatment } & Range & $120-1000$ & $110-940$ & -3.554 & $0.001^{*}$ \\
\hline & Mean \pm SD & $322.333 \pm 203.888$ & $638.000 \pm 340.353$ & & \\
\hline Differences & Mean \pm SD & $69.333 \pm 63.893$ & $62.000 \pm 102.285$ & & \\
\hline Paired test & $P$-value & $<0.001^{*}$ & 0.088 & & \\
\hline
\end{tabular}

*significant

Table 11 Best cut off for pretreatment Angiopoietin-2 in predicting fibrosis regression

\begin{tabular}{lllllll}
\hline & Cutoff & Sens. & Spec. & PPV & NPV & Accuracy \\
\hline Ang-2 & $\leq 680$ & 93.33 & 70.00 & 90.3 & 77.8 & $81 \%$ \\
\hline
\end{tabular}




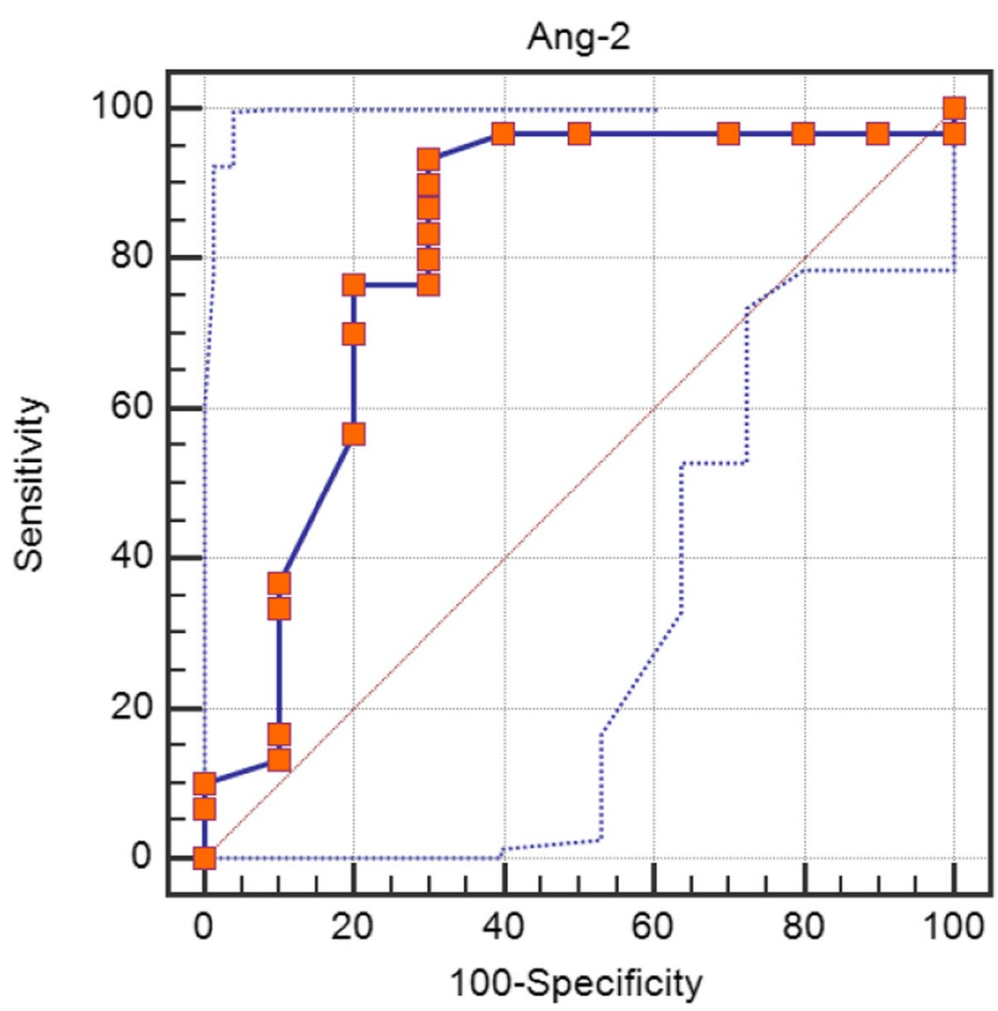

Fig. 2 ROC curve of pretreatment Angiopoietin-2 value in prediction of fibrosis regression

fibrosis degree during and shortly after DAAs termination from 12.65 to $8.55 \mathrm{kPa}$.

While using biomarker-based fibrosis methods, APRI and FIB-4 scores showed a statistically significant improvement of fibrosis at SVR12. These results agreed with previous studies by Knop et al. [22] and Elsharkawy et al. [23], revealing significant improvement of such scores on achieving SVR.

A possible explanation for the decline in liver stiffness in cirrhotic HCV patients who achieved SVR is that healing comprises two phases. The first phase is stiffness decline, which is influenced by a reduction in necroinflammatory activity, while the second phase may be more influenced by the regression of fibrosis [24].

Angiogenesis and fibrosis are critical phenomena in the pathogenesis of chronic liver disease and hepatocarcinogenesis. However, it is unclear whether angiogenesis occurs concurrently with the onset of fibrosis or plays a causal role in fibrosis. Angiogenesis causes collagen fibril condensation, which results in mechanical forcemediated activation of hepatic stellate cells (HSCs) [25]. Angiogenic factors, such as Ang-2, are secreted by liver sinusoidal endothelial cells (LSECs), which may contribute to angiogenesis and the activation of HSCs, as well as the advancement of liver fibrosis [26].
In this study, elevated levels of baseline Ang-2 were detected at advanced stages of liver fibrosis with a $p$ value of 0.001. Its levels were also significantly higher in F4 patients compared to F0-F3 collectively with a $p$ value of $<0.001$. These findings agreed with those of HernándezBartolomé et al. [15], who discovered that Ang-2 serum levels increased progressively with the advancement of fibrosis stages, and that Ang-2 was accurate in differentiating between different fibrosis stages (F1, F2, and F3) in $107 \mathrm{CHC}$ patients. It also agreed with Makhlouf et al. [27], who discovered that Ang-2 serum levels had an independent, significantly positive relationship with liver fibrosis stages.

Consequently, significantly positive correlations were noted between baseline Ang-2 and AST, ALT, total bilirubin, and INR, whereas a negative correlation was noted with serum albumin.

These results were in conformity with previous data from Osawa et al. [28], who noted that Ang-2 was positively correlated with prothrombin time, LSM, and albumin bilirubin score but negatively correlated with platelets and albumin, which indicates that Ang-2 reflects the degree of liver fibrosis and function. Therefore, Ang2 , angiogenesis, and fibrosis were all linked in $\mathrm{CHC}$ patients. 
Moreover, regarding fibrosis degree measurement, significantly positive correlations between baseline Ang-2 and LSM, FIB-4, APRI, and portal vein diameter were noted, and these agreed with Hernández-Bartolomé et al. [3] and Kawagishi et al. [29], who reported that Ang-2 levels were substantially correlated with LSM and spleen size, which are parameters associated with portal hypertension, implying that portal hypertension-induced slow blood flow may enhance Ang-2 expression.

As a result, Osawa et al. [28] compared the performance of Ang-2 in the prediction of liver fibrosis to that of the well-known fibrosis prediction indices, FIB-4 index, APRI score, and LSM, where Ang-2 discriminated F2-F4 patients from F1 patients with a superior performance to that of FIB-4 and APRI. However, LSM showed superior predictive ability.

In the current study, we found that the best cutoff value of baseline Ang-2 in the discrimination of liver cirrhosis (F4) from F0-F3 was $>630 \mathrm{pg} / \mathrm{ml}$ with $85.71 \%$ sensitivity and $84.85 \%$ specificity.

On achievement of SVR12, Ang-2 levels significantly declined in all patients in comparison to baseline. With a significant reduction among F0-F3 patients ( $p$ value $<0.001$ ), yet the reduction in F4 patients yielded insignificant ( $p$ value 0.136 ). These results are in conformity with Osawa et al. [28] who explained this reduction by that improvement in inflammation by DAAs can reduce the angiogenic response of LSECs, resulting in decreased Ang-2 secretion.

In the present study, $75 \%(30 / 40)$ of patients experienced regression of the LSM based liver fibrosis stage and 25\% (10/40) experienced non-regression. Comparison of both groups revealed that higher AST, ALT, INR, and bilirubin, and lower albumin and platelet count were significantly associated with non-regression of fibrosis after successful HCV eradication. This agreed with Hernández-Bartolomé et al. [15] who demonstrated that age, platelet count, INR, AST, and GGT are significant independent variables linked to liver fibrosis.

The present results demonstrated that baseline advanced fibrosis stage (F4) and Ang-2 levels are significant determinants of non-regression after DAAs therapy. And this was in agreement with Kawagishi et al. [29], who reported the same results at SVR24. Also, Kawagishi et al. [19] followed patients for a longer duration and confirmed such results at SVR96.

Furthermore, Mauro et al. [6] discovered that pretreatment high hepatic venous pressure gradient and LSM are significant predictors of non-regression of liver fibrosis after SVR by DAAs in liver transplantation patients.

Ultimately, our results showed a significant reduction in Ang-2 levels after DAAs therapy among those who experienced regression of liver fibrosis ( $p$ value $<$ $0.001)$, yet, insignificant reduction in non-regression patients ( $p$ value 0.088 ).

Taking together the results of the current study, high baseline serum Ang-2 might predict non-regression in liver fibrosis after successful HCV eradication with DAAs. At a cut of $>680 \mathrm{pg} / \mathrm{ml}$, it showed $93.33 \%$ sensitivity and $70 \%$ specificity.

Interestingly, Lefere et al. [30] found that serum Ang-2 levels were significantly higher in NASH patients than in those with simple liver steatosis. Furthermore, in a NASH mouse model, inhibiting Ang-2 reduced hepatocyte ballooning and fibrosis.

Thus, Ang-2 inhibitors may be effective in reducing liver fibrosis progression and HCC occurrence in patients with elevated Ang-2 levels and non-regression of liver fibrosis after successful HCV eradication.

The limitations of this study are the small number of patients evaluated and the limited monitoring duration.

Therefore, further studies with a larger number of patients and a longer follow-up period after treatment are needed to validate the role of Angiopoietin-2 as a useful predictor of fibrosis regression after successful HCV eradication.

\section{Conclusions}

Angiopoietin-2 can be a useful predictor of fibrosis regression in chronic $\mathrm{HCV}$ patients receiving directacting antiviral agents.

Elevated baseline Angiopoietin-2 and advanced fibrosis stages may predict non-regression of liver fibrosis.

\section{Abbreviations \\ HCV: Hepatitis C virus; CHC: Chronic hepatitis C; HCC: Hepatocellular carcinoma; DAAs: Direct-acting antiviral agents; SVR: Sustained virological response; VEGF: Vascular endothelial growth factor; Ang-1: Angiopoietin 1; Ang-2: Angiopoietin 2; NCCVH: National Committee for Control of Viral Hepati- tis; APRI: AST to platelet Ratio Index; FIB-4: Fibrosis-4 score; NPV: Negative pre- dictive value; PPV: Positive predictive value; LSM: Liver stiffness measurement; kPa: Kilopascal; EOT: End of treatment; HSCs: Hepatic stellate cells; LSECs: Liver sinusoidal endothelial cells; SPSS: Statistical Package for the Social Sciences; PV: Portal vein diameter.}

\section{Acknowledgements \\ The authors are grateful to the staff members of Ain Shams University's Clinical Pathology, and Gastroenterology and Hepatology departments.}

\section{Authors' contributions}

Al suggested the research topic, completed a final review of the collected data, and contributed to the manuscript preparation. TME made a significant contribution to the manuscript's writing and critical revision. SHH assisted in the collection of data. HSR contributed to the interpretation of statistical analyses of the obtained data. The submitted manuscript was revised and approved by all authors.

\section{Funding}

There was no specific grant for this research. 


\section{Availability of data and materials}

On request, the corresponding author will provide the data used in the current work.

\section{Declarations}

\section{Ethics approval and consent to participate}

This study was in accordance with the ethical principles of the 1975 Helsinki Declaration that was granted by the local Ethics Committee of Ain Shams University Faculty of medicine (FWA 000017585) December 2018. Participants gave their informed written consent before being enrolled in the trial, after being informed about the goal of the study.

\section{Consent for publication}

Participants provided written permission for the study's findings to be published.

\section{Competing interests}

There are no competing interests.

Received: 31 October 2021 Accepted: 21 November 2021

Published online: 11 December 2021

\section{References}

1. El-Shabrawi MH, Kamal NM, Mogahed EA et al (2020) Perinatal transmission of hepatitis C virus: an update. Arch Med Sci 16(6):1360-1369. https://doi.org/10.5114/aoms.2019.83644

2. Salomone F, Petta S, Micek A et al (2020) Hepatitis C virus eradication by direct antiviral agents abates oxidative stress in patients with advanced liver fibrosis. Liver Int 40(11):2820-2827

3. Hernández-Bartolomé Á, López-Rodríguez R, Borque MJ et al (2016) Angiopoietin-2/angiopoietin-1 as non-invasive biomarker of cirrhosis in chronic hepatitis C. World J Gastroenterol 22(44):9744-9751

4. Suda G, Sakamoto N (2021) Recent advances in the treatment of hepatitis C virus infection for special populations and remaining problems. J Gastroenterol Hepatol 36:1152-1158

5. Tachi Y, Hirai T, Miyata A et al (2015) Progressive fibrosis significantly correlates with hepatocellular carcinoma in patients with a sustained virological response. Hepatol Res 45(2):238-246

6. Mauro E, Crespo G, Montironi C et al (2018) Portal pressure and liver stiffness measurements in the prediction of fibrosis regression after sustained virological response in recurrent hepatitis C. Hepatology 67(5):1683-1694

7. Abd-El-Moety HA, Magour GH, Maharem DA et al (2011) Evaluation of serum angiopoietin-II in HCV related glomerulonephritis. Alexandria J Med 47:97-103

8. Eklund L, Oslen BR (2006) Tie receptors and their angiopoietin ligands are context-dependent regulators of vascular remodeling. Exp Cell Res 312(5):630-641

9. Moon WS, Rhyu KH, Kang MJ et al (2003) Overexpression of VEGF and Angiopoietin 2: A key to high vascularity of hepato-cellular carcinoma? Mod Pathol 16(6):552-557

10. El-Akel W, El-Sayed MH, El Kassas M et al (2017) National treatment programme of hepatitis C in Egypt: Hepatitis C virus model of care. J Viral Hepat 24(4):262-267. https://doi.org/10.1111/jvh.12668

11. Karić U, Pešić-Pavlović I, Stevanović G et al (2018) FIB-4 and APRI scores for predicting severe fibrosis in chronic hepatitis $C$ - a developing country's perspective in DAA era. J Infect Dev Ctries 12(3):178-182. https://doi.org/ 10.3855/jidc.10190

12. Isaac A, Mo'nes AA, Wassfy WE et al (2019) Soluble CD163 as a surrogate marker of fibrosis regression in chronic HCV patients receiving direct antiviral agents. EJHBMT 6(7):43-55. https://doi.org/10.21608/ejhbmt. 2019.192016

13. Castera L, Vergniol J, Foucher J et al (2005) Prospective comparison of transient elastography, fibrotest, APRI, and liver biopsy for the assessment of fibrosis in chronic hepatitis C. Gastroenterology 128:343-350

14. Dash S, Aydin Y, Widmer KE et al (2020) Hepatocellular Carcinoma Mechanisms Associated with Chronic HCV Infection and the Impact of Direct-Acting Antiviral Treatment. J Hepatocell Carcinoma 7:45-76. https://doi.org/10.2147/JHC.S221187

15. Hernández-Bartolomé Á, López-Rodríguez R, Rodríguez-Muñoz Y et al (2013) Angiopoietin-2 serum levels improve noninvasive fibrosis staging in chronic hepatitis C: a fibrogenic-angiogenic link. PLoS One 8(6):e66143. https://doi.org/10.1371/journal.pone.0066143

16. Friedman SL (2008) Mechanisms of hepatic fibrogenesis. Gastroenterology 134:1655-1669

17. Fernandez M, Semela D, Bruix J et al (2009) Angiogenesis in liver disease. J Hepatol 50:604-620

18. Augustin HG, Koh GY, Thurston G et al (2009) Control of vascular morphogenesis and homeostasis through the angiopoietin-Tie system. Nat Rev Mol Cell Biol 10:165-177

19. Kawagishi N, Suda G, Kimura M et al (2021) Baseline elevated serum angiopoietin-2 predicts long-term non-regression of liver fibrosis after direct-acting antiviral therapy for hepatitis. C. Sci Rep 11:9207. https://doi. org/10.1038/s41598-021-88632-7

20. Van der Meer AJ, Maan R, Veldt BJ et al (2016) Improvement of platelets after SVR among patients with chronic HCV infection and advanced hepatic fibrosis. J Gastroenterol Hepatol 31(6):1168-1176

21. Bachofner JA, Valli PV, Kröger A et al (2017) Direct antiviral agent treatment of chronic hepatitis $C$ results in rapid regression of transient elastography and fibrosis markers fibrosis-4 score and aspartate aminotransferase-platelet ratio index. Liver Int 37:369-376

22. Knop V, Hoppe D, Welzel T et al (2016) Regression of fibrosis and portal hypertension in $\mathrm{HCV}$-associated cirrhosis and sustained virologic response after interferon-free antiviral therapy. J Viral Hepat 23:994-1002. https://doi.org/10.1111/jvh.12578

23. Elsharkawy A, Alem SA, Fouad R et al (2017) Changes in liver stiffness measurements and fibrosis scores following sofosbuvir based treatment regimens without interferon. J Gastroenterol Hepatol 32:1624-1630. https://doi.org/10.1111/jgh.13758

24. Mohammed MA, Omar NM (2019) Assessment of liver fibrosis after direct-acting antiviral therapy in compensated and decompensated HCVrelated liver diseases. IJIRMS 4(4):256-263

25. Liu L, You Z, Yu H et al (2017) Mechanotransduction-modulated fibrotic microniches reveal the contribution of angiogenesis in liver fibrosis. Nat Mater 16(12):1252-1261

26. Poisson J, Lemoinne S, Boulanger C et al (2017) Liver sinusoidal endothelial cells: Physiology and role in liver diseases. J Hepatol 66(1):212-227

27. Makhlouf MM, Osman MA, Saleh SA et al (2016) Serum angiopoietin-2 as a noninvasive diagnostic marker of stages of liver fibrosis in chronic hepatitis C patients. Egypt J Intern Med 28:140-148

28. Osawa Y, Yoshio S, Aoki Y et al (2021) Blood angiopoietin-2 predicts liver angiogenesis and fibrosis in hepatitis C patients. BMC Gastroenterol 21(1):55. https://doi.org/10.1186/s12876-021-01633-8

29. Kawagishi N, Suda G, Kimura M et al (2020) High serum angiopoietin-2 level predicts non-regression of liver stiffness measurement-based liver fibrosis stage after direct-acting antiviral therapy for hepatitis C. Hepato Res 50:671-681. https://doi.org/10.1111/hepr.13490

30. Lefere S, Van de Velde F, Hoorens A et al (2019) Angiopoietin-2 promotes pathological angiogenesis and is a therapeutic target in murine nonalcoholic fatty liver disease. Hepatology 69:1087-1104

\section{Publisher's Note}

Springer Nature remains neutral with regard to jurisdictional claims in published maps and institutional affiliations. 